\title{
Cell-free DNA mutations as biomarkers in breast cancer patients receiving tamoxifen
}

\author{
Maurice P.H.M. Jansen ${ }^{1}$, John W.M. Martens ${ }^{1}$, Jean C.A. Helmijr ${ }^{1}$, Corine M. Beaufort ${ }^{1}$, \\ Ronald van Marion'2, Niels M.G. Krol'2,3, Kim Monkhorst ${ }^{2}$, Anita M.A.C. Trapman- \\ Jansen $^{1}$, Marion E. Meijer-van Gelder ${ }^{1}$, Marjolein J.A. Weerts ${ }^{1}$, Diana E. Ramirez- \\ Ardila $^{1}$, Hendrikus Jan Dubbink ${ }^{2}$, John A. Foekens ${ }^{1}$, Stefan Sleijfer ${ }^{1}$, Els M.J.J. Berns ${ }^{1}$ \\ ${ }^{1}$ Department of Medical Oncology and Cancer Genomics, Erasmus MC Cancer Institute, Rotterdam, The Netherlands \\ ${ }^{2}$ Department of Pathology, Erasmus MC Cancer Institute, Rotterdam, The Netherlands \\ ${ }^{3}$ Cancer Computational Biology Center, Rotterdam, The Netherlands
}

Correspondence to: Stefan Sleijfer, email: s.sleijfer@erasmusmc.nl

Keywords: breast cancer, tamoxifen therapy, targeted next generation sequencing, cell-free DNA, disease progression

Received: February 12, 2016

Accepted: May 08, 2016

Published: May 30, 2016

\section{ABSTRACT}

The aim was to identify mutations in serum cell-free DNA (cfDNA) associated with disease progression on tamoxifen treatment in metastatic breast cancer (MBC). Sera available at start of therapy, during therapy and at disease progression were selected from 10 estrogen receptor (ER)-positive breast cancer patients. DNA from primary tumor and normal tissue and cfDNA from minute amounts of sera were analyzed by targeted next generation sequencing (NGS) of 45 genes (1,242 exons). At disease progression, stop-gain single nucleotide variants (SNVs) for CREBBP (1 patient) and SMAD4 (1 patient) and non-synonymous SNVs for AKAP9 (1 patient), PIK3CA ( 2 patients) and TP53 (2 patients) were found. Mutations in CREBBP and SMAD4 have only been occasionally reported in breast cancer. All mutations, except for AKAP9, were also present in the primary tumor but not detected in all blood specimens preceding progression. More sensitive detection by deeper re-sequencing and digital PCR confirmed the occurrence of circulating tumor DNA (ctDNA) and these biomarkers in blood specimens.

\section{INTRODUCTION}

It is increasingly appreciated that the genetic make-up of tumors forms one of the main determinants for outcome to systemic treatments in cancer patients [1]. There is also accumulating evidence that primary tumor characteristics can greatly differ from those of the metastases [2]. This may underlie the relatively poor association of molecular characteristics of primary tumors with outcome in MBC. It is therefore likely that genetic variants important for treatment decision making should be determined in specimens from metastatic tumor rather than from primary tumor tissue. In addition, the genetic constitution of a tumor lesion is not fixed but constantly changes, in particular under treatment pressure. As novel DNA mutations can cause resistance to systemic treatments, longitudinal monitoring of these mutations during treatment is crucial to detect resistance at an early stage and, if possible, to adjust treatment based on the emerging mutations.
DNA from primary and metastatic tumor cells can be detected as cfDNA in the peripheral blood of cancer patients. This cfDNA is therefore a very attractive tool to establish mutational changes occurring in tumor cells in a minimal invasive manner. Its great promise in this respect was recently reviewed [3]. For example, in patients with metastatic KRAS wild-type colorectal cancer treated with an anti-EGFR antibody, blood analyses showed that the appearance of $K R A S$ mutants, conferring resistance against anti-EGFR antibodies, preceded progressive disease with up to 10 months [4]. Likewise, in breast cancer patients mutations in the estrogen receptor (ESR1) have been hardly detected in primary tumors but are currently frequently reported in plasma from patients with metastatic disease that acquired resistance to aromatase inhibitor therapy [5-8]. In the current study, we aimed to identify tumor-specific mutations in cfDNA that associate with disease progression on tamoxifen in $\mathrm{MBC}$. 


\section{RESULTS}

\section{Detection of DNA changes}

As we were interested in cfDNA mutations that potentially associate with treatment outcome in a particular patient, we characterized DNA changes in serum taken at disease progression in $10 \mathrm{MBC}$ patients who received firstline tamoxifen (Supplementary Table S1). After applying our selection criteria on called variants, 18 cfDNA changes were identified at disease progression which were not detected in normal tissue DNA nor reported by the 1000 Genome database. Of these, 3 variants were only seen in blood specimens and not in the corresponding primary tumor whereas 15 variants were also detectable in the primary tumor. Twelve DNA changes in 6 patients were shown to associate with treatment outcome (Figure 1). Of these, 9 tumor-specific DNA changes were present at disease progression and in the primary tumor but not in all blood specimens preceding progression (Table 1).

\section{Pathogenic somatic single nucleotide substitutions}

The 12 DNA changes included 5 synonymous and 7 non-synonymous SNVs. Almost all algorithms predicted the missense SNVs for $C D H 1$, PIK3CA and $T P 53$ (p.V41G; p.R148G) as pathogenic and for $A K A P 9$, $C R E B B P$ and $S M A D 4$ predominantly as not pathogenic (Supplementary Table S2). Moreover, the SNVs in PIK3CA and TP53 have been reported as cancer-specific mutations.

\section{Re-sequencing at $1 \%$ detection limit of missense SNVs}

Next the identified non-synonymous SNVs were selected for re-sequencing since only these translate into amino acid changes, which might alter the biological function of the encoded protein and as a result might affect clinical outcome. All specimens were re-sequenced for 1 missense SNV found in blood only and 5 missense SNVs found in primary tumors at diagnostic levels, i.e. higher than $10 \%$. The re-sequencing confirmed the initial results for $A K A P 9$ p.H562Q in patient 1, CREBBP p.E1321X in patient 6, SMAD4 p.Y353X, TP53 p.V41G, and PIK3CA H1047L in patient 7, and TP53 p.R148G in patient 8. Moreover, PIK3CA exon 20 re-sequencing identified another SNV, i.e. p.H1047R. This SNV was seen at disease progression and all other blood specimens of patient 1 and in the primary tumors of patients 1,2 , and 7 (Supplementary Table S3).

\section{Digital PCR evaluation at $0.05 \%$ detection limit of PIK3CA mutations}

The re-sequencing results for PIK3CA were verified by digital PCR using mutation-specific assays
(Supplementary Table S3). The p.H1047L mutation was evaluated and confirmed in all specimens of patients 7 and 10 , but was additionally seen in serum at start of therapy of patient 10. The p.H1047R mutation was evaluated in all primary tumors as well as in blood specimens of patients 1 and 2. Digital PCR confirmed the occurrence of this mutation in all evaluated blood specimens and primary tumors, except in the primary tumor of patient 7 .

\section{cfDNA mutations and disease development}

For patient 1 additional blood specimens available between diagnosis of primary tumor and metastatic lesions were evaluated by NGS and digital PCR (Figure 2). Re-sequencing demonstrated AKAPY and PIK3CA mutations at similar magnitudes in blood specimens taken around the occurrence of metastatic lesions. It also detected PIK3CA mutant reads in blood preceding the metastasis, however, in less than 10 reads. Digital PCR confirmed this PIK3CA mutation in blood taken 6 years after diagnosis of primary disease but two years before diagnosis of metastatic lesions. At the time metastatic lesions were recognized, the blood had a large number of copies with this mutation, which dropped after 2 months of first-line tamoxifen therapy, but increased towards therapy resistance after 6 months treatment.

\section{DISCUSSION}

This exploratory study is to our knowledge the first to report on sequential monitoring of serum cfDNA in a homogenous setting of MBC-patients receiving first-line tamoxifen therapy. In total 12 variants for 6 patients were identified in cfDNA at disease progression, including 3 variants that were only found in blood specimens but not in the primary tumor and 9 variants detected in corresponding primary tumor but not in all blood specimens preceding progression. Because of their putative biological relevance, we confirmed the identified missense mutations by re-sequencing and by digital PCR.

Out of these, missense mutations in PIK3CA, TP53, SMAD4 and CREBBP were present both at time of progression and in the primary tumor. COSMIC reported mutations in breast cancer most frequently in PIK3CA and TP53 while occasionally in CREBBP and SMAD4 with our variants for the latter two genes not earlier described. Mutations in all these genes have been found in hormone-resistant breast cancer [9]. The presence of PIK3CA and TP53 mutations in longitudinally collected blood specimens correlated with treatment outcome to PI3K-inhibitors and aromatase inhibitors and was associated with the clinical course of disease $[10,11]$. $C R E B B P$ and SMAD4 encode proteins that bind to ER as co-activator [12] and co-repressor [13], respectively, suggesting a putative role in endocrine therapy resistance $[13,14]$. However, the effect of the CREBBP stop-gain 
mutation revealed in our study remains to be established. The SMAD4 p.Y353X stop-gain mutation resides within the $\mathrm{MH} 2$ domain, a mutational hotspot [15] related to a loss of function, detrimental for TGFb signaling, and poor disease outcome [16]. Importantly, above variants at

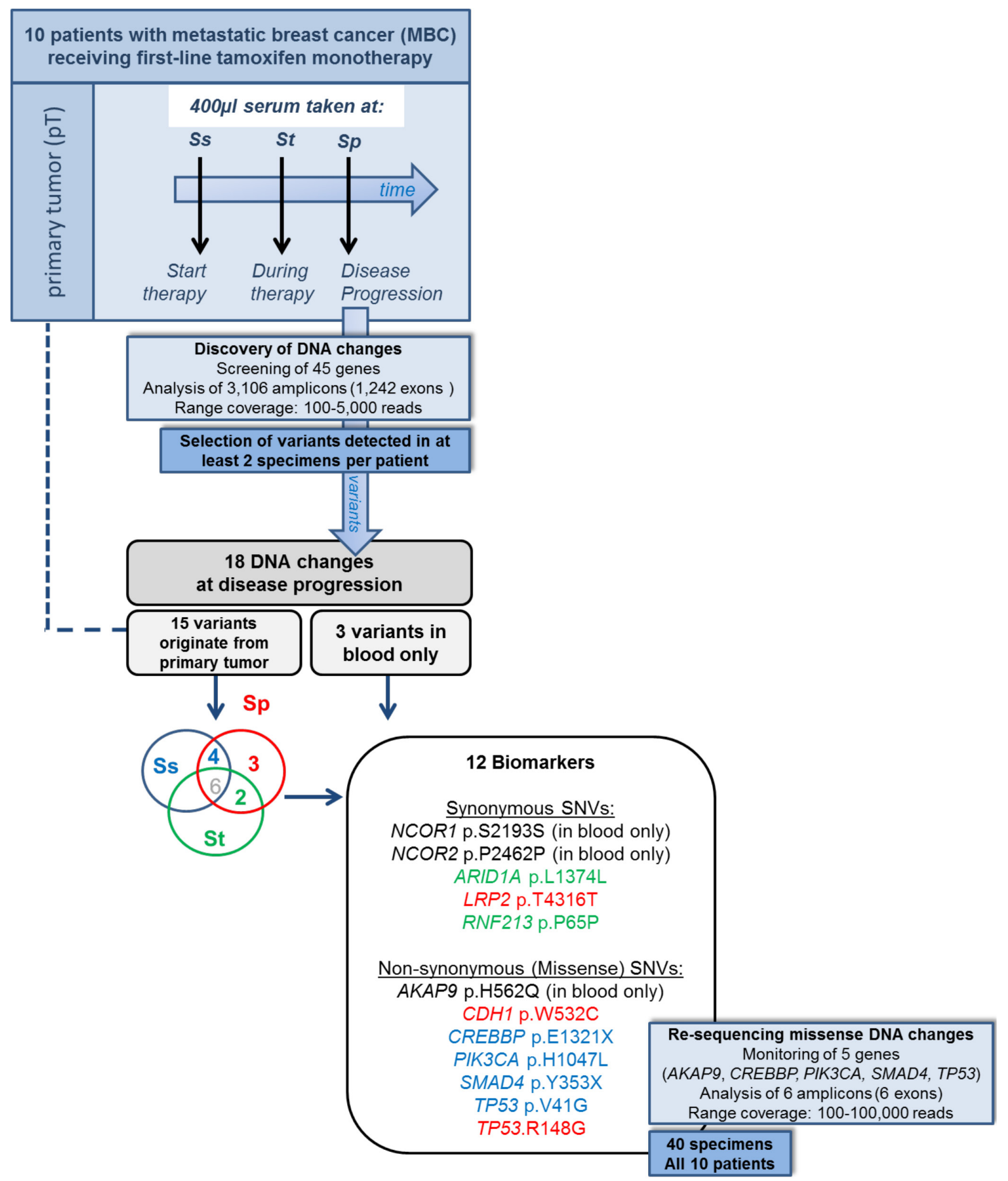

time of progression likely reflect only tumor load in the blood. The $A K A P 9$ p.H562Q missense mutation was not seen in the primary tumor and might have been missed due to tumor cell heterogeneity. Alternatively, this mutation might originate from metastatic lesions or acquired due

Figure 1: Study design and discovered DNA changes. Targeted ion-PGM (re-)sequencing was performed on DNA isolated from primary tumors and blood specimens from 10 metastatic breast cancer patients who received tamoxifen as first-line therapy. Cell-free DNA (cfDNA) was isolated from $400 \mu 1$ serum taken at start (Ss), during therapy (St) and at disease progression (Sp). Analysis revealed 12 biomarkers including 9 single nucleotide variants (SNVs) detected at progression and in primary tumor but not in all preceding blood specimens. The SNVs originating from the primary tumor are presented in red when only seen at Sp, in green when seen at Ss and Sp, and in blue when seen at St and Sp. 
Table 1: 12 cfDNA mutations identified as biomarkers in 6 metastatic breast cancer patients receiving first-line tamoxifen therapy ${ }^{1}$

\begin{tabular}{|c|c|c|c|c|c|c|c|c|c|c|c|c|c|}
\hline \multicolumn{14}{|c|}{ Results obtained in cfDNA ${ }^{2}$ and calculated per $1 \mathrm{ml}$ serum } \\
\hline & & \multicolumn{3}{|c|}{ Primary Tumor $(\mathrm{pT})$} & \multicolumn{3}{|c|}{ At start therapy (Ss) } & \multicolumn{3}{|c|}{ During therapy (St) } & \multicolumn{3}{|c|}{ At disease progression (Sp) } \\
\hline Gene & $\begin{array}{c}\text { Amino Acid } \\
\text { change }\end{array}$ & $\begin{array}{l}\text { DNA input } \\
\text { (in ng) }\end{array}$ & $\begin{array}{l}\text { variant frequency } \\
\text { (in \%) }\end{array}$ & $\begin{array}{c}\text { number } \\
\text { mutant } \\
\text { copies per } 1 \\
\text { ng DNA }\end{array}$ & $\begin{array}{l}\text { yield cfDNA } \\
\quad \text { (in ng) }\end{array}$ & $\begin{array}{c}\text { variant } \\
\text { frequency } \\
\text { (in \%) }\end{array}$ & $\begin{array}{c}\text { number } \\
\text { mutant copies } \\
\text { per } 1 \mathrm{ml} \\
\text { serum } \\
\end{array}$ & $\begin{array}{l}\text { yield cfDNA } \\
\text { (in ng) }\end{array}$ & $\begin{array}{l}\text { variant frequency } \\
\text { (in \%) }\end{array}$ & $\begin{array}{c}\text { number } \\
\text { mutant } \\
\text { copies per 1 } \\
\text { ml serum } \\
\end{array}$ & $\begin{array}{l}\text { yield cfDNA } \\
\text { (in ng) }\end{array}$ & $\begin{array}{c}\text { variant } \\
\text { frequency (in \%) }\end{array}$ & $\begin{array}{c}\text { number } \\
\text { mutant copies } \\
\text { per } 1 \mathrm{ml} \\
\text { serum } \\
\end{array}$ \\
\hline${\text { Patient } \mathbf{~}^{3}}$ & & 16.6 & & & 30.8 & & & 17.0 & & & 16.3 & & \\
\hline NCOR2 & p.P2426P & & 0 & 0 & & 0 & 0 & & 2 & 103 & & 3 & 148 \\
\hline$A K A P 9$ & p.H562O & & 0 & 0 & & 16 & 1493 & & 17 & 876 & & 2 & 99 \\
\hline Patient 6 & & 15.8 & & & 23 & & & 29.7 & & & 24 & & \\
\hline RNF213 & p.P65P & & 0 & 0 & & 0 & 0 & & 0 & 0 & & 2 & 145 \\
\hline$C D H I$ & p.W532C & & 0 & 0 & & 0 & 0 & & 0 & 0 & & 1 & 73 \\
\hline CREBBP & p.E1321X & & 23 & 65 & & 2 & 139 & & 0 & 0 & & 4 & 291 \\
\hline Patient 7 & & 14.8 & & & 14.8 & & & 7.3 & & & 17.5 & & \\
\hline PIK3CA & p.H1047L & & 25 & 76 & & 2 & 89 & & 0 & 0 & & 7 & 371 \\
\hline$S M A D 4$ & p.Y353X & & 17 & 52 & & 8 & 358 & & 0 & 0 & & 4 & 212 \\
\hline TP53 & p.V41G & & 35 & 106 & & 3 & 134 & & 0 & 0 & & 2 & 106 \\
\hline $\begin{array}{l}\text { Patient } 8 \\
\end{array}$ & & 13.0 & & & 17.5 & & & 24.3 & & & 113.8 & & \\
\hline NCORI & p.S2193S & & 0 & 0 & & 0 & 0 & & 4 & 294 & & 4 & 1379 \\
\hline$L R P 2$ & p.T4316T & & 10 & 35 & & 0 & 0 & & 0 & 0 & & 2 & 689 \\
\hline$R N F 213$ & p.P65P & & 2 & 7 & & 0 & 0 & & 3 & 220 & & 3 & 1034 \\
\hline $\mathrm{CDHI}$ & p.W532C & & 2 & 7 & & 0 & 0 & & 0 & 0 & & 1 & 345 \\
\hline$T P 53$ & p.R148G & & 35 & 121 & & 0 & 0 & & 0 & 0 & & 3 & 1034 \\
\hline Patient 9 & & 9.8 & & & 34.0 & & & 21.0 & & & 10.8 & & \\
\hline ARIDIA & p.L1374L & & 57 & 261 & & $50^{4}$ & 5152 & & 60 & 3818 & & 48 & 1564 \\
\hline Patient 10 & & 12.2 & & & 6.8 & & & 10.5 & & & 10.3 & & \\
\hline$C D H I$ & p.W532C & & 3 & 11 & & 0 & 0 & & 0 & 0 & & 3 & 93 \\
\hline $\begin{array}{r}P I K 3 C A \\
P I A\end{array}$ & p. H1047L & & 43 & 158 & & 0 & 0 & & 0 & 0 & & 0 & 0 \\
\hline$T P 53$ & p.R148G & & 0 & 0 & & 0 & 0 & & 2 & 64 & & 0 & 0 \\
\hline
\end{tabular}

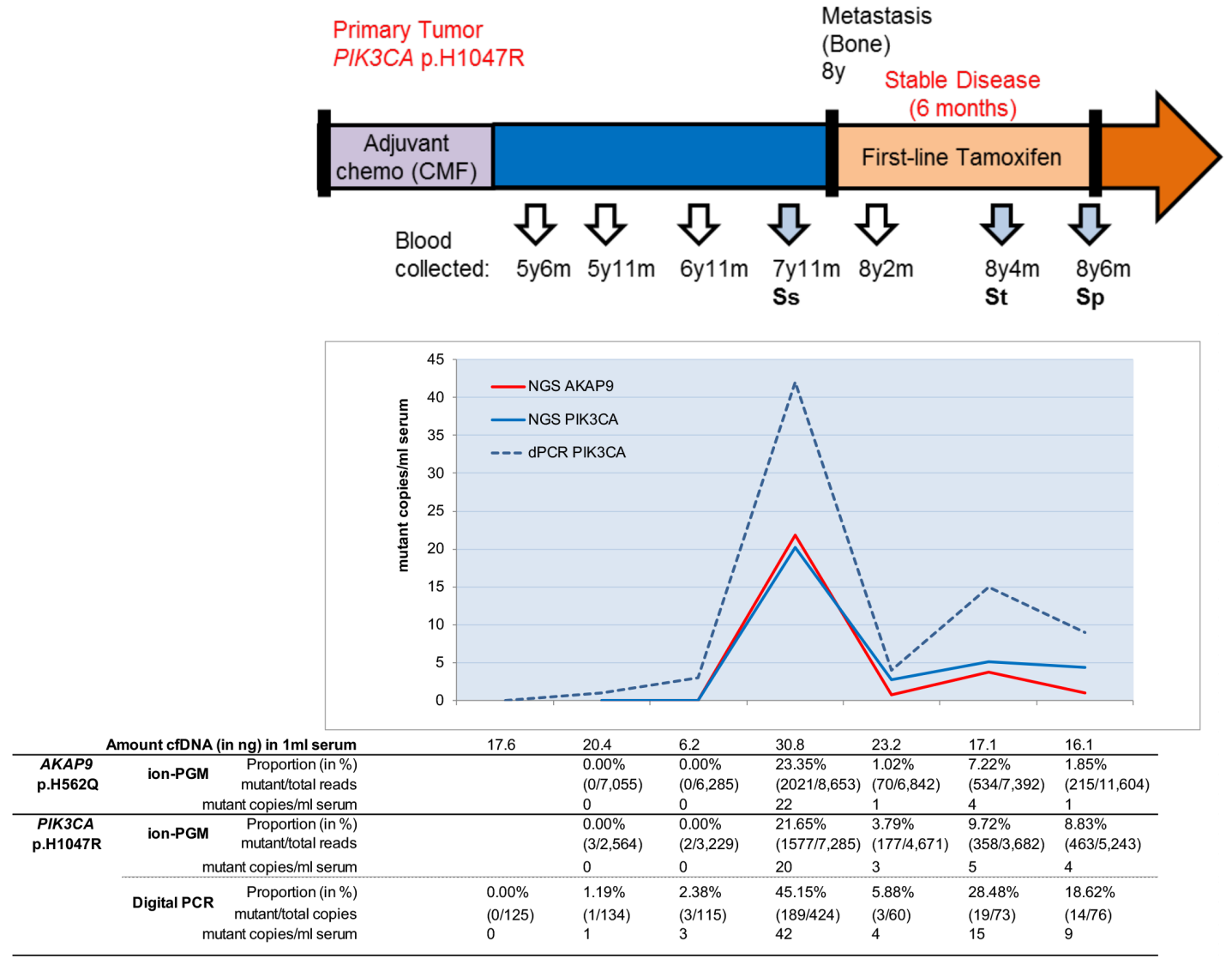

Figure 2: cfDNA missense mutations and disease development. The $A K A P 9$ and $P I K 3 C A$ mutations of patient 1 were evaluated in blood specimens during the course of disease. Sera collected five years after clinical diagnosis of breast cancer were evaluated by ionPGM resequencing and for PIK3CA in duplicate by digital PCR (dPCR). The p.H1047R mutation was observed at low magnitude in blood taken five years after diagnosis of primary disease and already two years before radiological diagnosis of metastatic lesions. Although sometimes low numbers of PIK3CA mutant copies were detected, all were independently observed after ion-PGM resequencing and in two separate digital PCR reactions. All proportions except for the sample at 5y11m were above the limit of detection. 
to treatment pressure. Variants in $A K A P 9$ have been described repeatedly in COSMIC and as SNPs associated with increased breast cancer risk [17], but the particular variant found here has not yet been reported. It is currently unknown whether, and if so, to which extent, all missense mutations actually contribute to resistance against tamoxifen. Many of the mutations are probably bystander mutations due to genomic instability. Therapy resistance, however, may select for tumor cells with specific mutations adapting these cells to the hostile environment, resulting in the survival of fittest and ultimately driving tumor progression [18].

Our study differs from previous studies using ionPGM targeted NGS on cancer tissue and liquid biopsies to identify tumor-specific DNA changes. Earlier studies [19-21] evaluated 200 amplicons of the commercially available hotspot cancer panel whereas we examined fifteen-fold more amplicons. These studies detected mutations in both plasma and tissue for 27 of 34 cancer patients [20], or like our study, in half of the cancer patients $[19,21]$ and evaluated plasma specimens collected within a 16 month time-frame after primary tumor tissue was obtained. We instead sequenced and identified mutations in minute cfDNA amounts isolated from serum collected at least 3 years after diagnosis of primary disease. Mutations in low DNA amounts might be missed due to the limited number of genomic equivalents present and corresponding higher limit of detection. Retrospective studies, such as our own, collected mainly limited blood quantities which will often result in minute cfDNA amounts available for analysis. Furthermore, our serum samples have been stored at $-80^{\circ} \mathrm{C}$ for more than 18 years, demonstrating that long-term stored routinely collected sera are suitable for cfDNA isolation and subsequent molecular characterization.

To define ctDNA mutations in blood associated with disease progression on tamoxifen treatment, we screened for biomarkers seen at progression and the corresponding primary tumor but not in all preceding blood specimens in a particular patient. The mutation detection in blood depends on cfDNA quantities, with these quantities changing in time and reflecting tumor load in the course of disease. Our study showed overall no significant differences in blood cfDNA yields at different time-points, however, most mutations were detected in patients with the highest DNA yields at progression. Deeper re-sequencing confirmed the presence of the 6 missense SNVs in specimens of individual patients in which they were initially reported and absence from those which initially lack them. It also discovered an additional PIK3CA mutation, and examination of sequence reads revealed that the p.H1047R mutation was originally present in respective specimens but not called due to stringent settings, indicating that current thresholds are suboptimal for rare variant detection in cfDNA $[19,22]$. Digital PCR independently identified both PIK3CA mutations in blood specimens at higher frequencies than revealed by NGS and in additional specimens and as proof-of-principle even in blood taken years before diagnosis of the metastatic lesions.

In conclusion, our study demonstrates that targeted ion-PGM sequencing of cfDNA is applicable to discover mutations in archived serum samples. Deeper re-sequencing and digital PCR analyses enables more sensitive detection and monitoring of specific mutations in sequential blood specimens even in samples stored for over 18 years and in minute amounts of cfDNA. Further studies are warranted to investigate whether detection of ctDNA in tamoxifen-treated metastatic breast cancer patients can be used to detect disease progression at an early stage and whether the identified variants play a role in tamoxifen resistance.

\section{MATERIALS AND METHODS}

Materials and methods are described briefly below, details are found in the appendix.

\section{Patient and sample collection}

This retrospective study investigated fresh frozen primary tumor tissue and sequential sera taken from 10 $\mathrm{MBC}$ patients who received tamoxifen as first-line therapy for distant metastatic disease (Figure 1). Blood specimens were selected at start of tamoxifen therapy (Ss), during therapy (St), and at disease progression (Sp). From 6 patients formalin fixed paraffin embedded (FFPE) macrodissected normal tissue was available and analyzed. The study was approved by the medical ethics committee (MEC 02.953), performed according to the Code of Conduct of Medical Scientific Societies (www.federa. org/codes-conduct) and followed REMARK guidelines where possible [23]. Clinicopathological characteristics are presented in Supplementary Table S4.

\section{DNA isolation, quantification, and sequencing}

DNA from tumor and normal tissue specimens was extracted as described previously [24, 25]. The MagnaPure Compact nucleic acid isolation kit (Roche Diagnostics) was applied to isolate cfDNA from $400 \mu \mathrm{l}$ serum. DNA yields and concentrations were quantified with a Qubit ${ }^{\circledR} 2.0$ fluorometer (Thermo Scientific). The cfDNA input amounts of each sample were used to establish the genomic equivalents and limits of detection for subsequent molecular analyses (Supplementary Tables S5 and S6). Semiconductor sequencing was performed using the Ion Torrent Personal Genome Machine (IonPGM) and consumables, kits, software packages and protocols provided by the manufacturer (Thermo Scientific). Briefly, $10 \mathrm{ng}$ tissue DNA and minute amounts cfDNA (range: $165-573 \mathrm{pg}$ ) were used as input for library 
preparation and sequenced with a custom-made gene panel. Ion AmpliSeq Library Preparation Kit 2 and Ion PGM Template OT2 200 kit were applied to generate libraries and templates, respectively. Ion Sequencing Kit v2 was used for sequencing on an Ion 318 chip.

\section{Custom gene panel}

The 45-gene panel (Supplementary Table S2) included the most frequently mutated genes for breast, colon, prostate and ovarian cancer reported in the catalogue of somatic mutations in cancer (Cosmic Release 67; http://cancer.sanger.ac.uk/cancergenome/projects/cosmic/). Thirty-nine genes were sequenced for all exons, 6 oncogenes for hotspot exons only. In total 3,106 amplicons (i.e. 1,242 exons; $\sim 255 \mathrm{~kb}$ ) were sequenced up to a read depth of 5,000x.

\section{Bio-informatics for variant detection and evaluation}

Raw data analyses, base calling and alignment were performed using Torrent Suite v4.0. Somatic low stringency filtering was applied in Variant Caller v4.16 (VC) to detect DNA changes when compared to reference genome hg19 (build 37). Variants were annotated by a custom pipeline including ANNOVAR (openbioinformatics.org/annovar) within Galaxy (galaxyproject.org). Only exonic variants with frequencies of $1 \%$ or higher and above the cfDNA-specific limit of detection were selected. Uniquely identified variants and those found in sequenced normal DNA or reported within the 1000-Genome database were excluded. These variants had to be sequenced without strand bias at a read depth of $100 \mathrm{x}$ or more and showing at least 10 mutant reads. Integrative Genomics Viewer (IGV) (http://www. broadinstitute.org/igv) was used for manual examination. Identified SNVs were evaluated with different in silico algorithms to predict the pathogenicity of the SNV on protein function. These tools are embedded in ANNOVAR and included SIFT, PolyPhen2, MutationTaster, FATHMM, GERP++, SiPhy and PhyloP [26].

\section{Re-sequencing and digital PCR analysis}

Exons of selected non-synonymous SNVs were re-sequenced for all specimens by ion-PGM after independent library preparation up to 100,000 reads depth, and evaluation was performed similar to the initial analysis. The PIK3CA genotype was verified with Taqman p.H1047L- and p.H1047R-specific assays and the QuantStudio ${ }^{\mathrm{TM}}$ 3D Digital PCR system (Thermo Scientific). Reaction mixtures, including tumor or serum DNA and QuantStudio ${ }^{\text {TM }}$ 3D Digital PCR Master Mix, were loaded on digital PCR chips with 20,000 wells, and cycled under standard conditions for 40 cycles. QuantStudio $^{\text {TM }}$ 3D analysisSuite ${ }^{\mathrm{TM}}$ determined the proportion mutant and wild-type templates.

\section{ACKNOWLEDGMENTS}

The authors MJ, JWM, JF, SS and EB have made substantial contributions to conception and design of the study. JH, CB, RM, NK, KM, AT, MMvG, MW, DR and HD were responsible for the acquisition and/or interpretation of data. The authors MJ, JWM, JF, SS, and EB were responsible for the study and wrote the manuscript whereas the authors JH, CB, RM, NK, KM, AT, MMvG, MW, DR and $\mathrm{HD}$ revised it on important contents. All authors have read and approved the final version of the manuscript and agree to be accountable for their expertise field of work. The authors are also especially grateful to Marcel Smid, Mieke Timmermans, Maxime Look, and Anieta Sieuwerts of the Department Medical Oncology, Irene Lurkin, Ellen Zwarthoff and Winand Dinjens of the Department Pathology, and Marian van Fessem and Ron van Schaik of the Department of Clinical Chemistry, all from Erasmus $\mathrm{MC}$, for their contribution and technical support.

\section{CONFLICTS OF INTEREST}

None of the authors has a conflict of interest.

\section{GRANT SUPPORT}

This work was supported in part by NWO-Cancer Genomics Netherlands (MJ, JWM, SS) and the NijbakkerMorra Foundation (MJ), Leiden, The Netherlands, Merck KGaA, Darmstadt, Germany (SS), and MRace (JH, EB, $\mathrm{MJ})$, Rotterdam, The Netherlands. MW receives research support from Philips Research.

\section{REFERENCES}

1. Vogelstein B, Papadopoulos N, Velculescu VE, Zhou S, Diaz LA Jr, Kinzler KW. Cancer genome landscapes. Science. 2013; 339:1546-1558.

2. Dupont Jensen J, Laenkholm AV, Knoop A, Ewertz M, Bandaru R, Liu W, Hackl W, Barrett JC, Gardner H. PIK3CA mutations may be discordant between primary and corresponding metastatic disease in breast cancer. Clin Cancer Res. 2011; 17:667-677.

3. Diaz LA Jr, Bardelli A. Liquid biopsies: genotyping circulating tumor DNA. J Clin Oncol. 2014; 32:579-586.

4. Misale S, Yaeger R, Hobor S, Scala E, Janakiraman M, Liska D, Valtorta E, Schiavo R, Buscarino M, Siravegna G, Bencardino K, Cercek A, Chen CT, et al. Emergence of KRAS mutations and acquired resistance to anti-EGFR therapy in colorectal cancer. Nature. 2012; 486:532-536.

5. Schiavon G, Hrebien S, Garcia-Murillas I, Cutts RJ, Pearson A, Tarazona N, Fenwick K, Kozarewa I, LopezKnowles E, Ribas R, Nerurkar A, Osin P, Chandarlapaty S, et al. Analysis of ESR1 mutation in circulating tumor DNA demonstrates evolution during therapy for metastatic breast cancer. Sci Transl Med. 2015; 7:313ra182. 
6. Wang P, Bahreini A, Gyanchandani R, Lucas PC, Hartmaier RJ, Watters RJ, Jonnalagadda AR, Trejo Bittar HE, Berg A, Hamilton RL, Kurland BF, Weiss KR, Mathew A, et al. Sensitive Detection of Mono- and Polyclonal ESR1 Mutations in Primary Tumors, Metastatic Lesions, and Cell-Free DNA of Breast Cancer Patients. Clin Cancer Res. 2016; 22:1130-1137.

7. Fanning SW, Mayne CG, Dharmarajan V, Carlson KE, Martin TA, Novick SJ, Toy W, Green B, Panchamukhi S, Katzenellenbogen BS, Tajkhorshid E, Griffin PR, Shen Y, et al. Estrogen receptor alpha somatic mutations Y537S and D538G confer breast cancer endocrine resistance by stabilizing the activating function-2 binding conformation. Elife. 2016; 5.

8. Niu J, Andres G, Kramer K, Kundranda MN, Alvarez RH, Klimant E, Parikh AR, Tan B, Staren ED, Markman M. Incidence and clinical significance of ESR 1 mutations in heavily pretreated metastatic breast cancer patients. Onco Targets Ther. 2015; 8:3323-3328.

9. Toy W, Shen Y, Won H, Green B, Sakr RA, Will M, Li Z, Gala K, Fanning S, King TA, Hudis C, Chen D, Taran T, et al. ESR1 ligand-binding domain mutations in hormoneresistant breast cancer. Nat Genet. 2013; 45:1439-1445.

10. Frenel JS, Carreira S, Goodall J, Roda Perez D, Perez Lopez R, Tunariu N, Riisnaes R, Miranda S, Figueiredo I, Nava Rodrigues D, Smith A, Leux C, Garcia-Murillas I, et al. Serial Next Generation Sequencing of Circulating Cell Free DNA Evaluating Tumour Clone Response To Molecularly Targeted Drug Administration. Clin Cancer Res. 2015.

11. Guttery DS, Page K, Hills A, Woodley L, Marchese SD, Rghebi B, Hastings RK, Luo J, Pringle JH, Stebbing J, Coombes RC, Ali S, Shaw JA. Noninvasive Detection of Activating Estrogen Receptor 1 (ESR1) Mutations in Estrogen Receptor-Positive Metastatic Breast Cancer. Clin Chem. 2015; 61:974-982.

12. Green KA, Carroll JS. Oestrogen-receptor-mediated transcription and the influence of co-factors and chromatin state. Nat Rev Cancer. 2007; 7:713-722.

13. Wu L, Wu Y, Gathings B, Wan M, Li X, Grizzle W, Liu Z, Lu C, Mao Z, Cao X. Smad4 as a transcription corepressor for estrogen receptor alpha. J Biol Chem. 2003; 278:15192-15200.

14. Shou J, Massarweh S, Osborne CK, Wakeling AE, Ali S, Weiss H, Schiff R. Mechanisms of tamoxifen resistance: increased estrogen receptor-HER2/neu cross-talk in ER/ HER2-positive breast cancer. J Natl Cancer Inst. 2004; 96:926-935.

15. Tram E, Ibrahim-Zada I, Briollais L, Knight JA, Andrulis IL, Ozcelik H. Identification of germline alterations of the mad homology 2 domain of SMAD3 and SMAD4 from the Ontario site of the breast cancer family registry (CFR). Breast Cancer Res. 2011; 13:R77.

16. Kozak MM, von Eyben R, Pai J, Vossler SR, Limaye M, Jayachandran P, Anderson EM, Shaffer JL, Longacre T, Pai RK, Koong AC, Chang DT. Smad4 inactivation predicts for worse prognosis and response to fluorouracilbased treatment in colorectal cancer. J Clin Pathol. 2015; 68:341-345.

17. Milne RL, Burwinkel B, Michailidou K, Arias-Perez JI, Zamora MP, Menendez-Rodriguez P, Hardisson D, Mendiola M, Gonzalez-Neira A, Pita G, Alonso MR, Dennis J, Wang Q, et al. Common non-synonymous SNPs associated with breast cancer susceptibility: findings from the Breast Cancer Association Consortium. Hum Mol Genet. 2014; 23:6096-6111.

18. Blagosklonny MV. Oncogenic resistance to growth-limiting conditions. Nat Rev Cancer. 2002; 2:221-225.

19. Couraud S, Vaca-Paniagua F, Villar S, Oliver J, Schuster T, Blanche H, Girard N, Tredaniel J, Guilleminault L, Gervais R, Prim N, Vincent M, Margery J, et al. Noninvasive diagnosis of actionable mutations by deep sequencing of circulating free DNA in lung cancer from never-smokers: a proof-of-concept study from BioCAST/ IFCT-1002. Clin Cancer Res. 2014; 20:4613-4624.

20. Lebofsky R, Decraene C, Bernard V, Kamal M, Blin A, Leroy Q, Rio Frio T, Pierron G, Callens C, Bieche I, Saliou A, Madic J, Rouleau E, et al. Circulating tumor DNA as a non-invasive substitute to metastasis biopsy for tumor genotyping and personalized medicine in a prospective trial across all tumor types. Mol Oncol. 2015; 9:783-790.

21. Rothe F, Laes JF, Lambrechts D, Smeets D, Vincent D, Maetens M, Fumagalli D, Michiels S, Drisis S, Moerman C, Detiffe JP, Larsimont D, Awada A, et al. Plasma circulating tumor DNA as an alternative to metastatic biopsies for mutational analysis in breast cancer. Ann Oncol. 2014; 25:1959-1965.

22. Xu H, DiCarlo J, Satya RV, Peng Q, Wang Y. Comparison of somatic mutation calling methods in amplicon and whole exome sequence data. BMC Genomics. 2014; 15:244.

23. McShane LM, Altman DG, Sauerbrei W, Taube SE, Gion M, Clark GM, Statistics Subcommittee of NCIEWGoCD. REporting recommendations for tumor MARKer prognostic studies (REMARK). Breast Cancer Res Treat. 2006; 100:229-235.

24. Berns EM, Klijn JG, van Putten WL, van Staveren IL, Portengen H, Foekens JA. c-myc amplification is a better prognostic factor than HER2/neu amplification in primary breast cancer. Cancer Res. 1992; 52:1107-1113.

25. van Lier MG, Wagner A, van Leerdam ME, Biermann K, Kuipers EJ, Steyerberg EW, Dubbink HJ, Dinjens WN. A review on the molecular diagnostics of Lynch syndrome: a central role for the pathology laboratory. J Cell Mol Med. 2010; 14:181-197.

26. Liu X, Jian X, Boerwinkle E. dbNSFP v2.0: a database of human non-synonymous SNVs and their functional predictions and annotations. Hum Mutat. 2013; 34:E2393-2402. 